\title{
Correlation of Tumour Size with Nuclear Grade, Stage and Extracapsular Extension in Renal Cell Carcinoma
}

\author{
Authors \\ Dr Suma M T ${ }^{1}$, Dr Lovely Jose ${ }^{2}$ \\ ${ }^{1}$ Associate Professor Department of Pathology, Government Medical College, Thrissur Kerala, India \\ Mobile no: 9847678928. Email: suma1879@gmail.com \\ ${ }^{2}$ Assistant Professor, Department of Pathology, Government Medical College Thrissur, Kerala, India \\ Corresponding Author \\ Dr Lovely Jose \\ Assistant Professor, Department of Pathology, Government Medical College Thrissur, Kerala, India \\ Mobile no: 9349252524, Email: drlovelybino@gmail.com
}

\section{ABSTRACT}

Introduction: Renal cell carcinoma is malignancy of renal tubular epithelium with poor prognosis. We evaluated the association between size of tumor with nuclear grade, stage and extra capsular extension in Renal cell carcinoma as these are the most important parameters in the prognosis

Materials and Method: 30 nephrectomy specimens with a histopathological diagnosis of Renal cell carcinoma were included in the study. The size, stage, integrity of capsule and nuclear grade were assessed and correlated. Study was approved by the institutional ethical committee. Pearson correlation coefficient was doneusing SPSS program for data analysis.

Result: Large tumors showed extra capsular extension and higher nuclear grade with statistically significant correlation $(p=0.04)$ No significant correlation observed between size of tumor and stage.

Conclusion: Renal cell carcinoma with a large tumor size has higher grade disease and poor prognosis.

Keywords: Nephrectomy, Renal cell carcinoma, Fuhrman nuclear grade.

\section{Introduction}

Renal cell carcinoma is a malignancy of renal tubular epithelium. Most common type of renal malignancy in adults is renal cell carcinoma which accounts for $90-95 \%$ of primary malignancies of kidney. Average age at presentation and diagnosis is between 50-70 years with male to female ratio of $2: 1^{(1)}$ Renal cell carcinoma rarely can occur in children and young adults and the clinical behavior and morphological features are similar to adult Renal cell carcinoma ${ }^{(2)}$ Usual clinical presentation is with a triad of haematuria, flank pain, and renal mass. Other mode of presentations include weight loss, anaemia, fever, and symptoms caused by metastasis. The important risk factors identified are cigarette smoking, high blood pressure, obesity, and exposure to industrial chemicals. ${ }^{(3)}$ An association with Von Hippel - lindau disease is seen in occasional patients with Renal cell carcinoma ${ }^{(4)}$ Clinically these neoplasms have bad prognosis due to relative resistance to radiotherapy and chemotherapy and associated high chances of 
metastases $^{(5)} 5$ year survival rate is only $8 \%$ for stage $4,53 \%$ for stage $3,74 \%$ for stage 2 and $81 \%$ for stage 1 disease (source - The American Cancer Society)

The prognosis of Renal cell carcinoma is related to several clinicopathological factors like size of tumor, stage ,extra capsular extension, presence of metastases, invasion into renal veins or renal pelvis and nuclear grade of the tumour.For nuclear grading Fuhrman system ${ }^{(6)}$ and for staging 2002 American joint committee on Cancer version of the TNM system is commonly used. Fuhrman grading system has good correlation with survival in a large group of patients with good survival in grade 1 tumors and decreased survival in grade 4 tumors. Nuclear grading also has good correlation with surgical TNM staging. Size of primary tumor is very important in assessing the survival, small tumors $(<3 \mathrm{~cm})$ have good prognosis and large tumors more than $7 \mathrm{~cm}$ have bad prognosis $(7,6)$ Significant correlation between the size of RCC, stage, grade and morphological subtypes were observed in various studies in literature. ${ }^{(8)}$ Extra capsular extension was not seen smaller tumors measuring $<4 \mathrm{~cm}$ while larger tumors more than $7 \mathrm{~cm}$ showed increased frequency of extra capsular extension. ${ }^{(9)}$ In the TNM system of staging tumors are categorized according to size and many studies investigated different cut off sizes for the tumor and greatest diameter has shown maximum prognostic significance. In this study we correlated the size of tumor with the stage, extra capsular extension and nuclear grade of RCC as these are the important tumor related prognostic factors.

\section{Materials and Methods}

This cross sectional study was conducted in a tertiary patient care center in South India under the guidance of institutional research committee.30 cases of radical nephrectomy specimens with a histopathological diagnosis of Renal cell carcinoma were included in the study. Nephrectomy done for other malignancies like transitional cell carcinoma, pediatric neoplasms and non-neoplastic conditions were excluded from the study. Clinical data of the patient were collected by proforma given to the patient, chart review and from surgical records. Nephrectomy Specimens were fixed in $10 \%$ formalin for about 18-24hours and gross morphological features and size of tumor were noted. Specimens were examined for other abnormalities including invasion of perirenal fat, capsule, ureter, renal vessels. Sampling was done from tumor, capsule, renal pelvis, adjacent parenchyma, ureter, renal vessels and lymph nodes. The size of the tumor was defined as the longest diameter in centimeters. In case of multi focal tumors the size of the larger one was recorded. Tissue was processed, sectioned and histological subtyping and nuclear grading was done in hematoxylin and eosin stained sections. Fuhrman grading system used for nuclear grading and were graded into 4 groups6. In lesions having characteristics of two nuclear grades they were assigned the higher nuclear grade. Tumors were stratified into 2 categories according to the size of the tumor; Group A (tumors measuring 0-7cm) and Group B (tumors measuring more than $7 \mathrm{~cm}$ ) Tumors were pathologically staged according to the 2002 American joint committee on Cancer version of the TNM staging system ${ }^{(9,10)}$ and graded according to Fuhrman's nuclear grading. ${ }^{(6)}$ Statistical analysis done (Pearson correlation coefficient) to assess the association between tumor size with stage, extra capsular extension and nuclear gradeusing SPSS program. A P value less than 0.05 were considered significant.

\section{Observations}

83 cases of radical nephrectomies were included in this study.51cases (61\%) were malignancy and 32 cases $(39 \%)$ were non neoplastic lesions of kidney. Out of 51 cases of renal malignancies 58\% (30 cases) were Renal cell carcinoma, $21 \%$ were Transitional cell carcinoma and $16 \%$ were paediatric neoplasms. $71 \%$ of renal cell carcinoma patients were males and $29 \%$ were females with a $\mathrm{M}: \mathrm{F}$ ratio of $2.4: 1$ 


\section{JMSCR Vol||05||Issue ||08||Page 25982-25987||August}

Table 01 Types of Renal malignancy

\begin{tabular}{|l|c|c|}
\hline RENAL TUMOUR & NUMBER & PERCENTAGE \\
\hline RCC & 30 & 58 \\
\hline TCC & 11 & 21 \\
\hline WILMS & 6 & 11 \\
\hline CSS & 2 & 4 \\
\hline AML & 2 & 4 \\
\hline
\end{tabular}

Age of patients ranged from 24years to 70yrs, four patients were young adults in $20-40$ years of age. $45 \%$ of patients presented with flank pain, haematuria and renal mass, rest of patients with bonepain, infertility fever and urinary tract infection. The classic triad of mass, hematuria and flank pain were seen only in $6 \%$ of patients. $69 \%$ cases of renal cell carcinoma were on the right side and $31 \%$ were on the left side and all the cases of RCC were unilateral.

Table 02 Histologic Variants of RCC

\begin{tabular}{|l|c|c|}
\hline VARIANT & NUMBER & PERCENTAGE \\
\hline Clearcell & 22 & 70 \\
\hline Papillary & 3 & 10 \\
\hline SarcomatoidRcc & 2 & 7 \\
\hline Unclassified & 2 & 7 \\
\hline Chromophobe & 1 & 3 \\
\hline Total & 30 & 100 \\
\hline
\end{tabular}

All nephrectomy specimens were grouped into 2 groups according to the size of the tumor ie GROUP A tumors measuring $0-7 \mathrm{~cm}$ and GROUP $B$ tumors measuring more than $7 \mathrm{~cm}$.

$43 \%$ of RCC were Small tumors less than $7 \mathrm{~cm}$ in diameter and majority of them were lower stage tumors.

Table 03 RCC $0-7 \mathrm{~cm}$ (Group A)

\begin{tabular}{|l|c|c|c|}
\hline & SIZE & TNM STAGE & GRADE \\
\hline 1 & $4 X 4$ & 3 & 2 \\
\hline 2 & $4 X 4$ & 1 & 2 \\
\hline 3 & $4 X 4$ & 1 & 2 \\
\hline 4 & $4 \times 3$ & 1 & 3 \\
\hline 5 & $3 \times 3$ & 1 & 2 \\
\hline 6 & $1 X 1$ & 1 & 3 \\
\hline 7 & $6 \times 4$ & 1 & 1 \\
\hline 8 & $5 X 4$ & 1 & 2 \\
\hline 9 & $5 \times 4$ & 1 & 3 \\
\hline 10 & $7 \times 5$ & 2 & 2 \\
\hline 11 & $7 X 6$ & 2 & 2 \\
\hline 12 & $6 \times 5$ & 3 & 3 \\
\hline 13 & $6 X 4$ & 3 & 3 \\
\hline
\end{tabular}

$57 \%$ of Rcc were large tumors measuring more than $7 \mathrm{~cm}$ in diameter and they showed higher nuclear grade and predominantly were stage 2 tumors.

Table 04 RCC more than $7 \mathrm{~cm}$ (Group B)

\begin{tabular}{|l|c|c|c|}
\hline & SIZE & STAGE & NUCLEAR GRADE \\
\hline 1 & $8 \times 7$ & 3 & 2 \\
\hline 2 & $8 \times 6$ & 2 & 2 \\
\hline 3 & $8 \times 5$ & 2 & 3 \\
\hline 4 & $8 \times 7$ & 2 & 2 \\
\hline 5 & $8 \times 6$ & 2 & 1 \\
\hline 6 & $8 \times 5$ & 2 & 2 \\
\hline 7 & $8 \times 4$ & 2 & 2 \\
\hline 8 & $9 \times 4$ & 3 & 2 \\
\hline 9 & $9 \times 7$ & 3 & 3 \\
\hline 10 & $10 \times 7$ & 2 & 3 \\
\hline 11 & $10 \times 8$ & 2 & 3 \\
\hline 12 & $11 \times 8$ & 2 & 3 \\
\hline 13 & $10 \times 5$ & 3 & 3 \\
\hline 14 & $10 \times 6$ & 2 & 3 \\
\hline 15 & $12 \times 5$ & 2 & 2 \\
\hline 16 & $17 \times 12$ & 2 & 3 \\
\hline 17 & $20 \times 17$ & 2 & 4 \\
\hline
\end{tabular}

Predominant nuclear grade was Fuhrman grade 2 $(48 \%)$. Table 05 shows as the size increases nuclear grade also increases

Table 05 : Grade and size of Renal cell carcinoma

\begin{tabular}{|l|c|c|c|}
\hline \multirow{2}{*}{ GRADE } & \multicolumn{2}{|c|}{ TUMOR SIZE } & \multirow{2}{*}{ TOTAL \& PERCENTAGE } \\
\cline { 2 - 4 } & $0-7 \mathrm{~cm}$ & $>7 \mathrm{~cm}$ & \\
\hline 1 & 1 & 1 & $2(6 \%)$ \\
\hline 2 & 7 & 7 & $14(48 \%)$ \\
\hline 3 & 5 & 8 & $13(43 \%)$ \\
\hline 4 & 0 & 1 & $1(3 \%)$ \\
\hline
\end{tabular}

$77 \%$ of Renal cell carcinomas were iow stage tumors with a predominance of TNM stage 2 and $23 \%$ belongs to stage 3 .

\section{Table 06}

\begin{tabular}{|l|c|c|c|}
\hline \multirow{2}{*}{ STAGE } & \multicolumn{2}{|c|}{ TUMOR SIZE } & \multirow{2}{*}{ TOTAL } \\
\cline { 2 - 3 } & $0-7 \mathrm{~cm}$ & $>7 \mathrm{~cm}$ & 8 \\
\hline 1 & 8 & 0 & 15 \\
\hline 2 & 2 & 13 & 7 \\
\hline 3 & 3 & 4 & \\
\hline
\end{tabular}

\section{Pearson correlation}

Size of RCC and nuclear grade showed statistically significant correlation (pearson correlation coefficient $=0.37)$ and $\mathrm{P}(<0.04)$. 


\section{JMSCR Vol||05||Issue||08||Page 25982-25987||August}

Pearson Correlation: size and grade

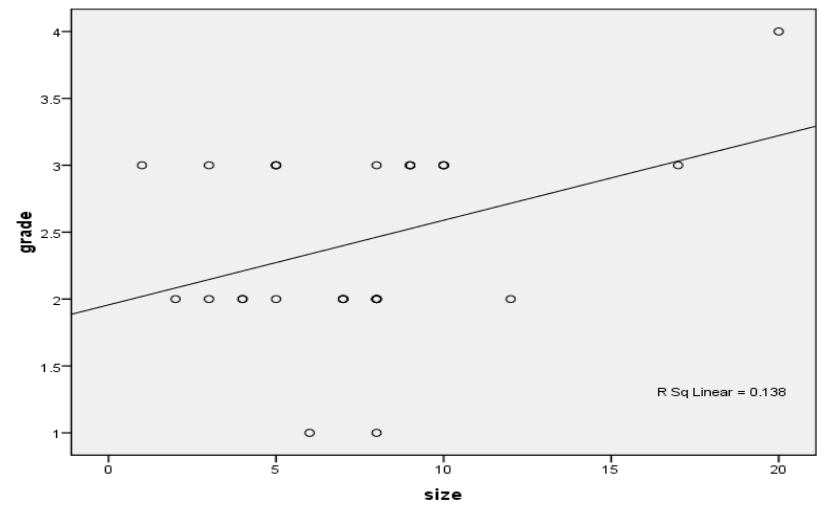

Pearson Correlation: size and grade

\begin{tabular}{|lc|c|c|}
\hline & & size new & Grade \\
\hline Size & Pearson Correlation & 1 & $.371^{*}$ \\
new & Sig. (2-tailed) & & .044 \\
& $\mathrm{~N}$ & 30 & 30 \\
\hline Grade & Pearson Correlation & $.371^{*}$ & 1 \\
& Sig. (2-tailed) & .044 & \\
& $\mathrm{~N}$ & 30 & 30 \\
\hline
\end{tabular}

* Correlation is significant at the 0.05 level (2-tailed).

The correlation between size of tumor and stage were not statistically significant (pearson correlation coefficient $<0.32$ and $p$ value $=0.085$ )

Correlation between size and stage of RCC

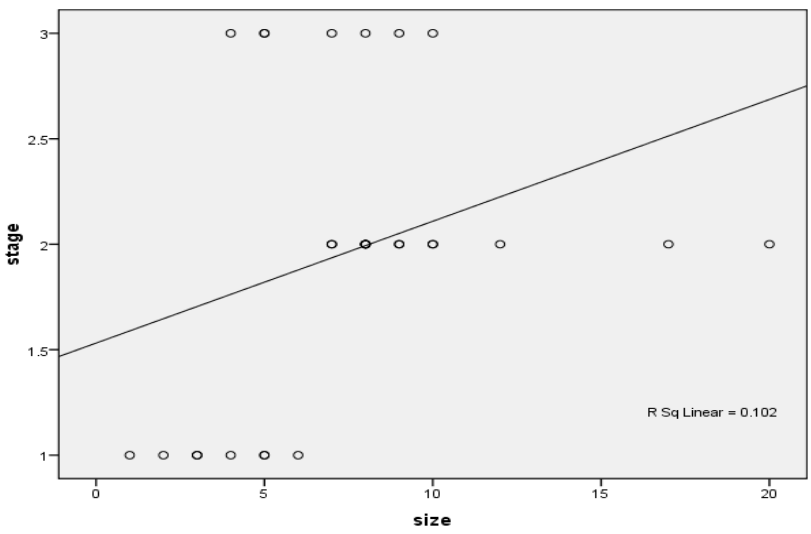

Pearson Correlation: size and stage

\begin{tabular}{|cc|c|c|}
\hline & & size new & Stage \\
\hline & Pearson Correlation & 1 & .320 \\
& Sig. (2-tailed) & & .085 \\
$\mathrm{~N}$ & 30 & 30 \\
\hline Stage & Pearson Correlation & .320 & 1 \\
& Sig. (2-tailed) & .085 & \\
& $\mathrm{~N}$ & 30 & 30 \\
\hline
\end{tabular}

Table 07 Tumors with extra capsular extension

\begin{tabular}{|l|c|c|c|}
\hline STAGE & $\begin{array}{c}\text { NUCLEAR } \\
\text { GRADE }\end{array}$ & SIZE & HISTOLOGY \\
\hline T3a & 2 & $8.5 \times 4$ & Clear cell RCC \\
\hline T3a & 2 & $8 \times 6$ & Clear cell RCC \\
\hline T3a & 2 & $7.5 \times 6.5$ & Clear cell RCC \\
\hline T3a & 2 & $4 \times 4$ & Clear cell RCC \\
\hline T3b & 2 & $10 \times 5$ & Clear cell RCC \\
\hline T3a N1 & 3 & 5.5 & Clear cell RCC \\
\hline T3a N2 & 3 & $9 \times 7$ & Clear cell RCC \\
\hline
\end{tabular}

Out of 30 cases of RCC 7 were stage 3 tumors with a distribution of T3a 4 cases,T3b 1case,T3a N1andT $3 \mathrm{~b} \mathrm{~N} 2$ one case each. Extra capsular extension was seen in large sized tumors.

\section{Discussion}

Renal cell carcinoma is a tumor of tubular epithelium with a poor prognosis. The overall survival of these patients depends on the extent of tumor involvement at the time of diagnosis with an overall 5-year survival rate of about $70 \%$. From the pathological and oncological point of view identification of patients with high tumor burden and high risk of disease progression is very important. There are several gross and microscopic tumor related prognostic factors including size, nuclear grade, stage of tumour, presence of metastasis and renal vein invasion. Several investigators documented that nuclear grade and size are the most important prognostic factors in RCC. Some other studies pointed out that TNM stage is more important in determining the outcome especially in intracapsular tumors. ${ }^{(11)}$

In this study we correlated the size of RCC with nuclear grade, stage of disease and extra capsular extension. We observed higher nuclear grade, and extra capsular extension in large sized tumors. As the size of tumour increased nuclear grade increased with a statistically significant correlation coefficient of 0.37 (Pearson correlation) and a significant $\mathrm{p}$ value $(\mathrm{P}=0.04)$ In a population based study conducted by Tomas Gudbjartssona, Sverrir Hardarsonb et al a strong correlation was found between grade and size with an increase of 0.06 in grade for every $1 \mathrm{~cm}$ increase in size of tumor $(\mathrm{p}<$ 
0.001). ${ }^{(12)}$ Hsu RM, Chandy et al observed in their study that larger lesions more than $5 \mathrm{~cm}$ showed higher TNM stage $(\mathrm{p}<0.001)$ and nuclear grade $(p<0.001)$ similar to present study. ${ }^{(13)}$ Similar to observations made by Sohaib Tariq et al extra capsular extension were seen in large tumors measuring more than $7 \mathrm{~cm}$ (T3 stage tumours) This observation is important in making decision whether to do a partial nephrectomy or radical nephrectomy. In contrast study conducted by Ljunberg B, Alandari FI et al observed that small renal cell carcinomas up to $3 \mathrm{~cm}$, including asymptomatic lesions, showed a significant incidence of high nuclear grade and tumor extension beyond the renal capsule. These findings support aggressive management of the small lesions. In our study $78 \%$ were low stage tumors (T1\&T2) with predominance of T2 tumors. There was no significant correlation between size of tumor with the stage probably due to the predominance of $\mathrm{T} 2$ tumors and low sample size.

According to Tsui $\mathrm{KH}$ et al tumor stage did not demonstrate an independent impact on renal cell carcinoma prognosis under multivariate analysis. Instead other factors such as ECOG status and grade of disease appeared to affect the survival. ${ }^{(14)}$ But independent of tumor grade the prognostic importance of TNM staging for RCC is well known. Gettman $\mathrm{M}$ T et al documented the close correlation of stage of RCC and the prognosis. ${ }^{(15)}$ When considering the therapeutical implications histological subtype is another valuable prognostic indicator for RCC. Among the morphological subtypes classical clear cell variant has got the worst prognosis. In our study most of RCCs (70\%) were with clear cell morphology and were large sized tumors with high nuclear grade at presentation compared to other morphological variants of Renal cell carcinoma like papillary RCC and chromophobe RCC.

\section{Conclusion}

In renal cell carcinoma size of tumor is directly related to the nuclear grade and extra capsular extension. Large tumors show higher nuclear grade and involvement of capsule. TNM Stage 2 and nuclear grade 2 tumors were the predominant type of Renal cell carcinoma in this study. The correlation between size of tumor with stage was not statistically significant and it may be due to low sample size and predominance of low stage tumors included in this study. In this era of advanced technology apart from grade and stage of the disease demonstration of molecular markers also play a pivotal role in the prognostication of renal cell carcinoma.

\section{Acknowledgment}

This research work could not be completed without the help of Dr. Sajna M.V,Assistant Professor of Community Medicine, .Govt Medical College Thrissur whose timely guidance and explanation of statistics were contributory.

\section{References}

1. Motzer RJ ,Banber NH , NanusDM.Renal cell carcinoma. N Engl J Med 1996,335 : 865-875.

2. Lack EE ,Cassady R, Sallan SE, Renal cell carcinoma in childhood and adolescence. A clinical and pathological study of 17 cases. J urol 1985,133;822-828.

3. Coughlin SS,NeatonJD,Randall B , Sengupta A,for the Multiple Risk Factor Intervention Trial Research Group Predictors of mortality from kidney cancer in 335,547 men screened for the Multiple Risk Factor Intervention Trial Cancer 1997, $79: 2171-2177$

4. Soloman D, Schwartz A, 1988, renal pathology in von Hippel - Lindau disease . Hum pathol 19: 1072-1079

5. Elson PJ , Witty RS , Trump DL 1988 Prognostic factors for survival in patients with recurrent or metastatic renal cell carcinoma . Cancer Res $48: 7310$ - 7313.

6. Fuhrman SA, Lasky LC, Limas C. Prognostic significance of morphologic parameters in renal cell carcinoma. Am J Surgical Pathol 1982, $6: 655-663$ 
7. Medei Ros L J, Gelb AB, Weiss LM .Renal cell carcinoma .Cancer 1988, 61: 1639 1651

8. Tabibi A I Parvin M . Correlation between size of renal cell carcinoma and grade stage and histological sub types Urol J . 2007 Winter ; 4[1] : $10-3$

9. Sohaib Tariq, Rizwan Ahmed, Waqas Tariq Butt et al 143 PakistanJournal of Medical and Health Science vol 1 No:4 Oct - Dec 2007

10. Cheville JC, Lohse CM, Zincke $\mathrm{H}$, etal. Comparison of outcome and prognostic features among histologic subtypes of Renal cell carcinoma. Am J Surg Pathol 2003;612624

11. L junberg B, Alandari FI, Rasmuson T, Roos G: Follow up guidelines for nonmetastatic renal cell carcinoma based on the occurrence of metastases after radical nephrectomy. BJU Int. 1999;84:405-11.

12. Tomas Gudbjartssona, Sverrir Hardarsonb: Histological Subtyping and Nuclear Grading of Renal Cell Carcinoma and Their Implications for Survival: A Retrospective Nation-Wide Study of 629 Patients. European Urology 48 (2005) 593600.

13. Hsu RM, Chan DY et al.Small renal cell carcinomas: correlation of size with tumourstage, nucleargrade, and histologic subtype.AJR Am J Roentgenol 2004;182: 551-7

14. Tsui KH, Shavarts O, Smith RB, et al. Prognostic indicators for renal cell carcinoma: a multivariate analysis of 643 patients using the revised 1997 TNM staging criteria. J Urol2000; 163:1090 -1095.

15. Gettman MT, Blute ML, Spotts B, Bryant S $\mathrm{C}$, Zinche H: Pathologic staging of renal cell carcinoma: significance of tumor classification with the 1997 TNM staging system. Cancer 2001; 91:354-361. 